\title{
O PADRÃO SILÁBICO CVC DO INGLÊS POR APRENDIZES BRASILEIROS
}

\section{THE ENGLISH SYLLABIC CVC PATTERN BY BRAZILIAN LEARNERS}

\author{
Anilda Costa Alves* \\ $U F P B$ \\ Daiane Aparecida Cavalcante ${ }^{* *}$ \\ $U F P B$ \\ Juliene Lopes Ribeiro Pedrosa*** \\ $U F P B$
}

Resumo: As línguas do mundo apresentam peculiaridades que podem causar estranhamento por parte dos aprendizes em L2, que, ao serem expostos a um novo sistema, podem demonstrar ineficácia quanto ao conhecimento do padrão base da língua-alvo. Dentre os aspectos a serem observados nesse processo, encontram-se os padrões silábicos, que podem distinguir-se da língua materna do aprendiz. Assim sendo, este trabalho objetivou investigar como falantes aprendizes brasileiros de inglês configuram o padrão silábico CVC do inglês, sendo estes distribuídos em dois grupos: aprendizes que receberam instrução, e aprendizes que não receberam instrução explícita, quanto aos aspectos fonético-fonológicos de tal estrutura. A base teórica apresenta as ideias de Alves (2012), Barbosa e Madureira (2015), Collischonn (2014), Pedrosa (2012) e Selkirk (1982), dentre outros. Os resultados demonstram que os grupos apresentaram estratégias distintas para a produção da sílaba CVC. Mesmo no grupo em que houve produções esperadas (sílaba CVC), os aprendizes pareceram compensar a ausência vocálica alongando a oclusiva em coda, demonstrando processos variáveis interessantes. Tal pesquisa visa contribuir com o ensino do inglês (L2), bem como demonstrar que diversas pistas acústicas verificadas no desenvolvimento linguístico de L2 não devem ser negligenciadas, pois podem fornecer respostas interessantes no percurso desenvolvido pelo aprendiz.

Palavras-chave: Sílaba CVC. Língua inglesa. Aprendizes brasileiros.

\begin{abstract}
The languages of the world have peculiarities that may be strange for L2 learners, who, when exposed to a new system, might demonstrate ineffectiveness in the phonological knowledge of the target language. Among the aspects to be observed in this process, there are the syllabic patterns of the target language, which might present phonotactic distinctions. Thus, this work aimed to investigate how Brazilian learners of English configure its syllabic structure. They were divided into two groups: learners
\end{abstract}

\footnotetext{
* Mestre e doutoranda em Linguística pelo Programa de Pós-Graduação em Linguística (PROLING)/ Universidade Federal da Paraíba (UFPB). ORCID: https://orcid.org/0000-0003-2365-8799. E-mail: anildacosta16@gmail.com.

${ }^{* *}$ Mestre e doutoranda em Linguística pelo Programa de Pós-Graduação em Linguística (PROLING)/UFPB. ORCID: https://orcid. org/0000-0001-9467-5559. E-mail: daiane.aparecida20@hotmail.com.

*** Doutora em Linguística pelo Programa de Pós-Graduação em Linguística (PROLING)/UFPB. Professora da UFPB. ORCID: https://orcid.org/0000-0003-4308-8762. E-mail: juliene.academia@yahoo.com.br.
} 
who received instruction and learners who did not receive explicit instruction regarding the phoneticphonological aspects of such a structure. The theoretical basis presents the ideas of Alves (2012), Barbosa and Madureira (2015), Collischonn (2014), Pedrosa (2012) and Selkirk (1982), among others. The results demonstrate that the groups presented different strategies for the production of the CVC syllable. Even in the group where there were expected productions (CVC syllable), the learners seemed to compensate for the vowel absence by lengthening the occlusive in coda position, showing interesting variable processes. Such research aims to contribute to the teaching of English (L2), and also to demonstrate that several acoustic clues that act in the linguistic development of L2 should not be neglected, since they can provide interesting answers in the course developed by the learner.

Keywords: CVC syllable. English language. Brazilian learners.

\section{INTRODUÇÃO}

A exposição a uma nova língua implica, geralmente, estranhamento por parte dos aprendizes. Na maioria dos casos, sobretudo em processo inicial, os falantes não conseguem estabelecer o porquê de tal estranhamento. Dentre as diferenças elencadas entre os diversos sistemas linguísticos, destaca-se um nível ainda pouco explorado no processo ensino-aprendizagem, o nível fonético-fonológico. Ao tratar dessa questão, neste texto, focalizamos como unidade de análise a sílaba como componente essencial do desenvolvimento fonético-fonológico da língua-alvo.

Este trabalho teve como objetivo geral analisar o padrão silábico do tipo consoante-vogal-consoante (CVC), em que a consoante final é um segmento oclusivo, em palavras da língua inglesa, produzidas por falantes brasileiros aprendizes de inglês como língua estrangeira. ${ }^{1} \mathrm{~A}$ escolha de tal padrão para esta pesquisa deu-se em decorrência da dificuldade encontrada para a realização do travamento silábico com segmentos oclusivos em final de sílaba, visto que, frequentemente, há a reestruturação do padrão CVC para CVCV, processo comum, sobretudo em níveis mais baixos de proficiência na língua-alvo.

Como objetivos específicos, pretendemos observar que estratégias os falantes utilizam para aproximar sua fala ao padrão fonológico da língua-alvo; verificar possíveis distinções entre falantes instruídos explicitamente, em detrimento de aprendizes que não receberam instrução explícita quanto aos aspectos fonético-fonológicos da língua inglesa, mais especificamente a estrutura silábica CVC; averiguar se os aprendizes transferem para a língua-alvo o padrão silábico CVCV, cânone do português brasileiro (PB). Para a análise das produções orais dos nossos informantes, utilizaremos o software Praat versão 6.0.35 (BOERSMA; WEENINK, 2017).

O trabalho tem, como referencial teórico, as contribuições de Pedrosa (2012) e Collischonn (2014), ao tratar da sílaba; Alves (2012), ao discorrer acerca da consciência fonológica no ensino de inglês como língua estrangeira; Barbosa e Madureira (2015), que trazem contribuições quanto à análise acústica do nosso objeto de estudo, a saber: a sílaba e a identificação dos elementos presentes nas produções dos aprendizes, bem como as estratégias fonéticas utilizadas por eles.

A pesquisa está distribuída da seguinte forma: na seção introdutória, trazemos o objetivo geral e os objetivos específicos a serem discutidos no limiar do trabalho. No referencial teórico,

\footnotetext{
${ }^{1}$ Embora exista a problemática quanto ao uso das terminologias “língua estrangeira”, “segunda língua” e “língua adicional”, neste trabalho, não traremos discussões aprofundadas acerca disso. Assim, em nossa pesquisa, tais termos poderão ser utilizados de forma intercambiável, fazendo referência à língua em desenvolvimento do aprendiz, diferentemente da língua materna.
} 
trataremos da sílaba e de seus elementos constituintes. Apresentamos também a consciência fonológica e sua importância para o desenvolvimento linguístico da língua-alvo e a Fonética Acústica como ferramenta essencial de análise dos dados orais dos aprendizes. Na seção dedicada à metodologia, explicitamos o passo a passo utilizado para a aplicação do experimento, coleta e análise dos dados. Posteriormente, na seção de resultados e discussão, destacamos as produções dos aprendizes, em que serão levantadas discussões acerca de tais achados. Por fim, na seção de considerações finais, retomaremos as questões apresentadas na introdução (objetivos geral e objetivos específicos), em que faremos reflexões acerca das produções encontradas nos dados dos aprendizes e como esses resultados interagem com a proposta de análise de tais objetivos, as limitações encontradas ao longo da pesquisa e suas contribuições para o desenvolvimento linguístico na língua-alvo.

Feitas essas considerações iniciais, podemos avançar o estudo para a seção em que abordaremos os aspectos teóricos considerados pertinentes para o empreendimento da nossa pesquisa.

\section{REFERENCIAL TEÓRICO}

Esta seção apresentará, conforme mencionado anteriormente, aspectos da sílaba e seus constituintes, bem como explanaremos a importância da consciência fonológica para o desenvolvimento linguístico em L2 e aspectos relacionados à Fonotática Acústica. Iniciemos por explorar aspectos relacionados à sílaba.

\section{A SÍLABA}

Embora, dentro da fonologia, não exista um consenso quanto às concepções de sílaba, neste trabalho tomaremos a noção de sílaba (Figura 1) proposta por Selkirk (1982).

Figura 1: Estrutura interna da sílaba

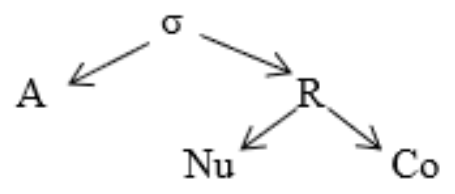

Fonte: Selkirk (1982, p. 344).

A sílaba ${ }^{2}$, representada pela letra grega sigma ( $\left.\sigma\right)$, é dividida em duas partes, quais sejam: ataque $^{3}$ (A) e rima (R). A rima, por sua vez, é dividida em núcleo (Nu) e coda (Co). Pedrosa (2012) destaca que as vogais, uma vez que são inerentemente mais sonoras do que as consoantes, de maneira geral, são os únicos segmentos a constituir o núcleo silábico. Em outras palavras, uma vogal, por si só, pode constituir uma palavra, já que pode ocupar sozinha o núcleo silábico, mas uma consoante isolada não o pode, pois não constitui o núcleo silábico.

\footnotetext{
${ }^{2}$ É importante destacarmos que, assim como não há consenso quanto à definição da sílaba dentro da fonologia, o mesmo ocorre para o estabelecimento ou não de uma hierarquia entre os elementos que a constituem. De acordo com o modelo de sílaba adotado nesta pesquisa, o de Selkirk (1982), há um processo de hierarquia entre os elementos, visto que uma ligação maior entre o núcleo e a coda do que entre o núcleo e o ataque.

${ }^{3}$ Algumas obras preferem o uso da terminologia onset, da língua inglesa, em detrimento de ataque.
} 
Há, no entanto, línguas, como é o caso da língua inglesa, em que as consoantes líquidas /r/ e /l/ também podem ocupar tal posição.

Os segmentos de margem, ou seja, que ocupam as posições de ataque e coda, mencionadas anteriormente, são as consoantes e glides. Com exceção da posição de núcleo, as demais posições podem ser preenchidas ou não. Isso significa dizer que o núcleo é a única posição de preenchimento obrigatório para a constituição silábica. Vejamos o exemplo da palavra "paz" [pas] (Figura 2), no português brasileiro, em que o segmento [p] é o ataque, [a] é o núcleo e [s] é a coda.

Figura 2: Exemplo de representação silábica - palavra “paz”, no português

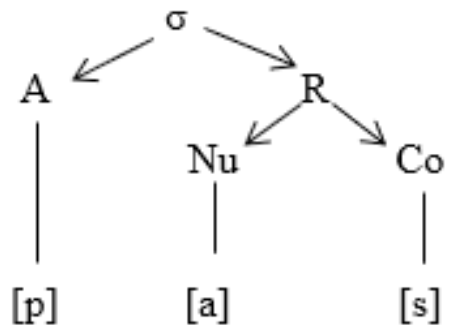

Fonte: As autoras.

Um ponto muito importante para o desenvolvimento da pesquisa em tela é o molde silábico, que, conforme apregoado por Collischonn (2014), refere-se a uma afirmação geral a respeito de como a estrutura das sílabas pode ser configurada nas línguas. Ressalta-se que a quantidade de elementos permitidos em cada posição e o tipo de segmento varia de uma língua para outra.

Com base em Pedrosa (2012) e Collischonn (2014), respectivamente, vejamos como se constituem os padrões silábicos do sistema linguístico do PB (Quadro 1) e do inglês (Quadro 2).

Quadro 1: Padrões silábicos do português brasileiro

\begin{tabular}{|l|l|}
\hline V & a \\
\hline VC & ar \\
\hline VCC & ins.tan.te \\
\hline CV & bo.la \\
\hline CVC & fes.ta \\
\hline CVCC & mons.tro \\
\hline CCV & tri.lha \\
\hline CCVC & plas.ma \\
\hline CCVCC & trans.por.te \\
\hline VV & ou.ro \\
\hline CVV & fai.xa \\
\hline CCVV & frou.xo \\
\hline CCVVC & claus.tro \\
\hline
\end{tabular}

Fonte: Adaptado de Pedrosa (2012). 
Quadro 2: Padrões silábicos do inglês

\begin{tabular}{|l|l|}
\hline VC & add \\
\hline CVC & back \\
\hline CCVC & step \\
\hline CVCC & land \\
\hline CCVCC & trend \\
\hline VV & I \\
\hline VVC & oil \\
\hline CVV & may \\
\hline CVVC & bike \\
\hline CVVCC & bind \\
\hline CCVVC & break \\
\hline CCVVCC & ground \\
\hline
\end{tabular}

Fonte: Adaptado de Collischonn (2014).

Apesar de ambas as línguas, o inglês e o português brasileiro, compartilharem o molde silábico CVC, conforme mostram os Quadros 1 e 2, há uma diferença quanto ao tipo de segmento comum na posição de coda de cada uma das línguas. Enquanto na língua inglesa é comum o segmento oclusivo em tal posição, como na palavra "bad” [bæd], do inglês, o português apresenta certa sensibilidade, visto que palavras com essa mesma estrutura, como "advogado”, “objeto”, são pouco frequentes, o que pode acarretar em produções do tipo [adivəgadu] e [jbizztu], respectivamente, reestruturando o molde CVC, para o molde consoante + vogal (CV), padrão canônico preferível do PB.

Outra característica importante é o peso silábico. Collischonn (2014) estabelece que as sílabas podem ser classificadas em leves ou pesadas. Tal classificação faz relação com a quantidade de elementos da rima e a posição da sílaba tônica na palavra. Uma rima composta apenas pelo núcleo é caracterizada como uma sílaba leve; em contrapartida, rima com mais de um elemento, sejam eles: vogal + consoante; vogal + glide (semivogal) ou por uma vogal longa, são caracterizadas como sílabas pesadas.

Após essa breve descrição da estrutura da sílaba, passemos a seção seguinte, em que fazemos uma reflexão acerca do papel da consciência fonológica para o desenvolvimento linguístico da língua inglesa, em destaque para o reconhecimento do padrão silábico CVC da língua inglesa, em que o segmento em coda é uma consoante oclusiva, como na palavra “book” [buk].

\section{A CONSCIÊNCIA FONOLÓGICA E O DESENVOLVIMENTO LINGUÍSTICO DO INGLÊS POR APRENDIZES BRASILEIROS}

A consciência fonológica (doravante CF) corresponde, conforme preconizam Chard e Dickson (1999), ao entendimento de como os sons da língua podem ser organizados e também manipulados. A organização diz respeito ao entendimento de como os segmentos são estruturados na sílaba, e a manipulação, por sua vez, envolve habilidades como o reconhecimento dos fonemas que compõem determinado sistema; segmentação da palavra em unidades menores, a 
saber, sílabas e fonemas; fornecimento de palavras que iniciam por um determinado segmento; troca de um segmento por outro, a fim de obter uma nova palavra, dentre outros. Dessa maneira, a CF envolve o uso deliberado dos elementos que formam o sistema linguístico.

Em língua materna, Alves (2012) destaca que a CF é de grande importância para alfabetizadores e fonoaudiólogos, visto que, por um lado, para a prática pedagógica, pode fornecer subsídios teóricos que visam seu aprimoramento, ao desenvolver no alfabetizando a sensibilidade ao sistema sonoro da língua e, como este se relaciona com a escrita, a relação grafema-fonema, favorecendo sua aquisição. Por outro lado, na prática clínica, fornece subsídios para corrigir determinados desvios fonológicos, os quais, se não trabalhados, podem acarretar insucesso na aquisição da escrita, entre outros fatores.

É, sobretudo, durante o processo de alfabetização na língua materna que o aprendiz desenvolve a CF, tornando-se apto para as habilidades citadas previamente. Assim, ao iniciar os estudos em uma L2, o aprendiz não vem vazio, conforme destaca Alves (2012), pois ele traz consigo sua bagagem linguística materna. É preciso, então, fornecer meios para que consiga desenvolver as mesmas habilidades, mas agora no novo sistema, fazendo-o compreender os aspectos fonológicos peculiares à nova língua. Alves (2012) ainda pontua que o fato de o aprendiz, durante a alfabetização linguística materna, ter desenvolvido sensibilidade ao seu sistema sonoro, pode favorecer o desenvolvimento da CF em L2, se tais aspectos forem explicitados durante o processo de aquisição.

Alves (2012) estabelece que a CF em L2 se dá em cinco níveis, a saber: a consciência dos padrões silábicos da L2, consciência das rimas na L2, consciência dos fonemas da L2, consciência dos alofones da L2 e consciência dos sons não distintivos na L1 e distintivos na L2, os quais, por sua vez, envolvem uma complexidade distinta. De tal forma, esses níveis vão se desenvolvendo em um continuum, não ocorrendo de maneira simultânea.

Ao tratar de uma língua estrangeira, é muito importante estar atento em como o aprendiz lida com os aspectos fonético-fonológicos da língua-alvo, visto que ele não apresenta domínios de CF para o novo sistema.

Dentre os cinco níveis de CF para o desenvolvimento da língua-alvo citados anteriormente, destacamos o nível silábico, que é foco de nossa pesquisa, posto que é no nível da sílaba que encontramos diversos processos fonológicos, que podem ser explicados pela ausência de domínio da CF.

Alves (2012) destaca que ter CF dos padrões silábicos da língua em desenvolvimento equivale a manipular as diversas formas como a sílaba pode ser estruturada. Nesse ínterim, o aprendiz pode, por exemplo, julgar determinadas produções orais como a sequência [kn] em ataque silábico do inglês como produções desviantes, visto que essa sequência não é suscetível de ocorrer na língua. Além disso, o aprendiz é capaz de estabelecer as fronteiras silábicas e, em especial na nossa pesquisa, é capaz de estabelecer que segmentos plosivos como [p, b, t, d, k, g] em posição de coda silábica são comuns na língua inglesa (molde CVC), o que não ocorre no sistema materno do aprendiz brasileiro.

O domínio da CF nesse prisma pode proporcionar ao aprendiz brasileiro de inglês maior eficácia em habilidades de produção e percepção fonológica. A ausência de tal domínio pode contribuir para a ocorrência de alguns desvios, como a troca de um fonema por outro, como, por exemplo, a palavra "think" [ $\theta i ̃ k]$, do inglês, que pode ser produzida como [fĩk] por um aprendiz brasileiro, por este não ter desenvolvido o nível fonêmico na L2; a inserção vocálica, como 
na palavra "book” [buk], produzida como [buki], pela ausência de domínio no nível silábico, entre outros desvios.

Concluídas essas breves considerações a respeito de como a CF pode favorecer o desenvolvimento na L2, trataremos, na seção seguinte, da Fonética Acústica e como esta pode contribuir para a obtenção de análises seguras do nosso objeto de estudo, o molde CVC da língua inglesa por aprendizes brasileiros, com consoantes oclusivas em posição de coda silábica.

\section{A FONÉTICA ACÚSTICA E O ENSINO DE INGLÊS COMO LÍNGUA ESTRANGEIRA}

A Fonética Acústica é de fundamental importância para o empreendimento deste trabalho, visto que a pesquisa tem como proposta averiguar como os aprendizes brasileiros produzem o molde silábico CVC da língua inglesa, em que a coda é uma consoante oclusiva. Assim, a análise acústica tem como função não deixar dúvidas quanto a tais produções, a partir da leitura espectrográfica. Em se tratando desse tipo de estudo, a análise apenas de oitiva pode ser influenciada por padrões advindos da língua materna, o que pode acarretar uma discussão pouco proveitosa.

Barbosa e Madureira (2015) estabelecem que o som exteriorizado é o resultado de um complexo processo envolvendo a produção da fala. Para obtenção desse resultado final, é necessária a atuação de três subsistemas: o subsistema respiratório, “combustível” responsável por toda a operação, visto que sem fluxo de ar não haveria som; o subsistema laríngeo, responsável pela fonação; o subsistema supralaríngeo, responsável pela fonodiversidade da fala. É neste último, a saber, no subsistema supralaríngeo, que os diversos sons da fala são moldados, mediante a ação dos articuladores.

As pistas acústicas, para a análise em questão, deverão pautar-se em como os aprendizes brasileiros estruturam a rima silábica com o molde CVC na língua inglesa. Para isso, o foco da análise será a produção de consoantes oclusivas e possíveis vogais após a oclusão. Os segmentos oclusivos são produzidos por meio de uma obstrução total no trato oral. Tal ação corresponde, no sinal acústico, em um ruído breve, identificado por uma espécie de "estria” escura no espectrograma. Observe, na Figura 3, o exemplo de uma consoante oclusiva produzida por um falante brasileiro.

Figura 3: Produção da consoante oclusiva [t], na palavra tata, produzida por falante brasileiro

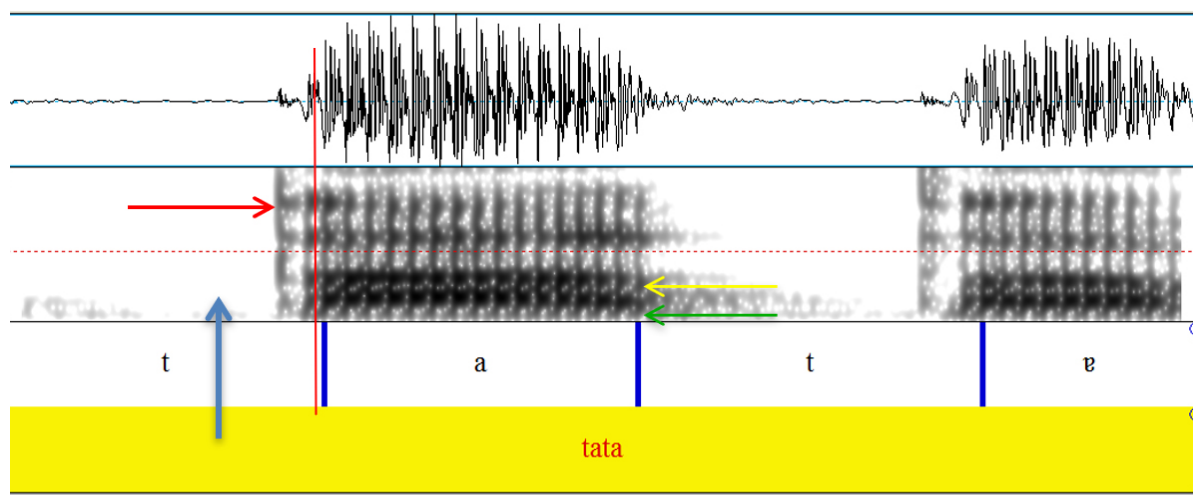

Fonte: As autoras. 
A fronteira delimitada pela linha vermelha supracitada, na Figura 3, representa um som oclusivo não vozeado [t]. A produção de um segmento oclusivo envolve características bem peculiares no espectrograma. Em primeiro lugar, há a ausência de energia, ocasionada pela obstrução total dos articuladores, o que ocasiona uma área "limpa” no espectrograma (seta azul); em seguida, há a soltura brusca de ar, o burst, essa soltura é identificada no espectrograma por meio de uma estria estreita (seta vermelha). Outra característica acústica desses sons é o tempo de duração para o vozeamento, denominado com ${ }^{4}$ VOT.

Barbosa e Madureira (2015) apontam que o VOT é definido como a diferença de tempo entre o instante em que as pregas vocais começam a vibrar e o momento de soltura do ar. Tal característica pode ser positiva, quando as pregas vocais começam a vibrar somente depois da soltura do ar, em oclusivas não vozeadas [p, t, k], ou negativa, quando a vibração das pregas vocais inicia antes da soltura, em sons oclusivos vozeados [b, d, g]. A barra de sonoridade também é uma das características acústicas desses sons. Localiza-se na parte inferior do espectrograma sempre que há vibração das pregas vocais. Assim, ela surge durante a produção de oclusivas vozeadas (setas vermelhas, Figura 4) e não está presente em oclusivas não vozeadas (seta azul, Figura 4). Veja, na Figura 4, a descrição da barra de sonoridade em segmentos oclusivos na palavra bicudo.

Figura 4: Barra de sonoridade em oclusivas vozeadas

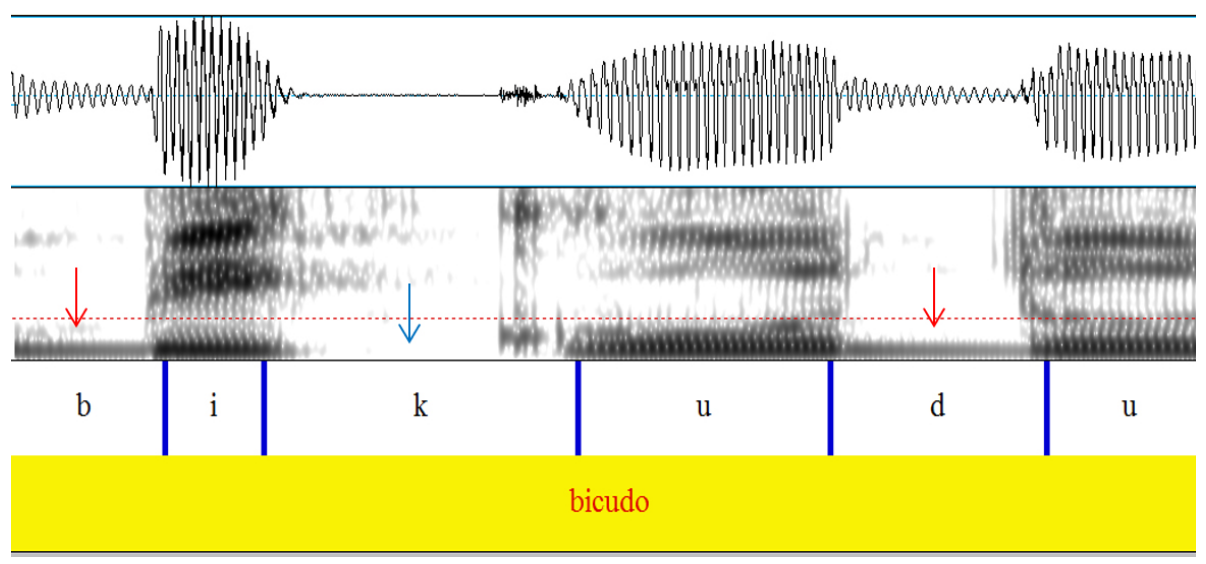

Fonte: As autoras.

Um segmento vocálico (som adjacente à consoante [t] na Figura 3) envolve o surgimento dos formantes. Tais eventos acústicos são identificados por linhas horizontais, de cor mais escura, que trazem características vocálicas preponderantes. O F1 (seta verde) é responsável pelo movimento de altura da mandíbula e carrega valores inversos (quanto mais baixa a vogal, mais alto o F1); o F2 (seta amarela) está relacionado ao recuo/avanço da língua (quanto mais alta e frontal a vogal, mais o F2 está afastado do F1). No caso das vogais posteriores [0, o, u], ambos os formantes, F1 e F2, estão mais próximos, em decorrência do arredondamento dos lábios. Essas características serão importantes quando analisarmos as produções silábicas dos

${ }^{4}$ Do termo em inglês Voice Onset Time. 
aprendizes, visto que tais produções poderão fornecer informações importantes acerca do desenvolvimento linguístico na língua-alvo.

Após essa breve apresentação sobre os instrumentos provenientes da Fonética Acústica e sua contribuição para a análise dos nossos dados, passemos para a próxima seção, a qual nos fornecerá os passos metodológicos seguidos no estudo.

\section{METODOLOGIA}

O estudo contou com 10 participantes brasileiros aprendizes de inglês (L2), divididos em dois grupos distintos: alunos que receberam instrução ${ }^{5}$ explícita quanto aos aspectos fonéticos-fonológicos da língua inglesa (grupo experimental - GE) e alunos que não receberam instrução explícita quanto aos aspectos fonético-fonológicos do inglês (grupo controle - GC). O GE recebeu treinamento durante um período de seis meses. Ambos os grupos eram compostos por estudantes de duas turmas distintas de $9^{\circ}$ ano (Ensino Fundamental - anos finais) de uma escola particular regular da cidade de Guarabira, localizada no estado da Paraíba, Brasil. A instrução não foi concentrada apenas nos padrões silábicos da língua, visto que tal ação poderia comprometer a coleta dos dados. Assim, os alunos puderam ter acesso a diversas peculiaridades fonológicas da língua-alvo tais como os fonemas, os padrões silábicos e rítmicos da língua-alvo.

Após o período de instrução no GE, os alunos foram submetidos à leitura de um pequeno texto redigido em língua inglesa, o qual continha palavras com o molde silábico CVC, com uma consoante oclusiva em coda, estrutura comum na língua inglesa, diferentemente do português brasileiro, visto que, apesar de haver algumas palavras com essa mesma estrutura, é de baixa frequência. A coleta foi realizada em um ambiente acusticamente tratado, por meio de um gravador do tipo Zoom H1 Handy Recorder 200m, com as seguintes configurações: Microfones: On-board Zoom H1 unidirectional Microphones; taxa de frequência de resposta dos microfones: 30 a 16000 Hz; taxa de amostragem: 44100 Hz; taxa de quantização: 16 bits.

Os participantes estavam cientes de que, caso não estivessem à vontade durante o procedimento de leitura, poderiam desistir a qualquer momento, e o material fornecido pelo participante desistente seria descartado. Nenhum dos informantes desistiu da coleta.

A caixa de texto ${ }^{6}$ a seguir traz o texto utilizado por Alves (2018, p. 101) para a leitura dos informantes do GE e do GC.

\footnotetext{
${ }^{5}$ A instrução acerca do molde silábico CVC, em que a coda é uma consoante oclusiva, envolveu tarefas de percepção e de produção. Nas tarefas de percepção, por exemplo, os aprendizes foram estimulados a julgar qual o som final de palavras produzidas por falantes nativos as quais eram expostos. Eles também ouviam pares de palavras, produzidas pelas pesquisadoras, e deveriam estabelecer qual das palavras de cada par não terminava com uma consoante oclusiva [buk - buki], por exemplo. Nas tarefas de produção, foram selecionadas cenas de séries preferidas pelos aprendizes, as quais continham o nosso objeto de estudo. Os aprendizes deveriam reproduzir as cenas, que eram gravadas e analisadas posteriormente pela professora, a qual fornecia dicas de como a estrutura silábica com molde CVC era comum na língua inglesa.

${ }^{6}$ Os itens em destaque na caixa de texto foram os selecionados para análise quanto ao molde silábico CVC no GC e GE.
} 


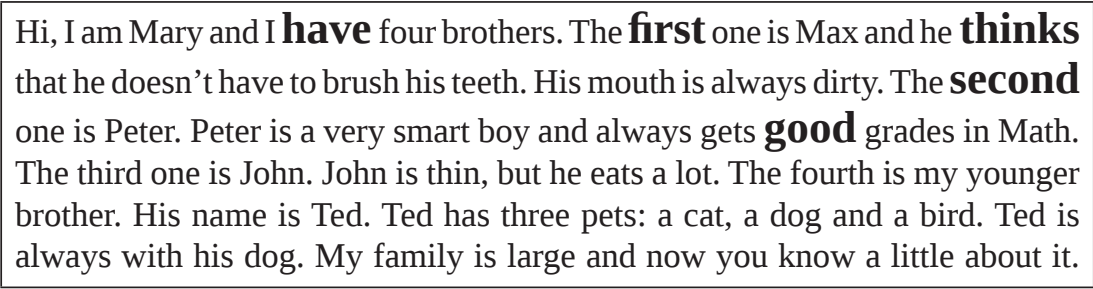

Thanks for reading!

Depois de coletados, os dados orais foram submetidos à análise acústica, por meio do software Praat - versão 6.0.356 (BOERSMA; WEENINK, 2017). A partir da observação dos eventos acústicos no espectrograma, pudemos constatar se houve ou não a reestruturação silábica aos moldes da sílaba do PB (CV). Em caso da não reestruturação, buscamos verificar, por meio de outras pistas acústicas, como a duração (em milissegundos) da consoante oclusiva em coda, se houve compensação em segmentos contíguos, como uma produção de oclusiva mais longa, em virtude de não produção da vogal de apoio.

A seguir, os resultados obtidos na pesquisa e as discussões levantadas acerca das estratégias utilizadas pelos informantes.

\section{RESULTADOS E DISCUSSÕES}

Das 50 produções obtidas (25 de cada grupo - GC vs. GE), algo nos chamou atenção. Os aprendizes brasileiros de inglês como L2 que receberam instrução quanto aos aspectos fonético-fonológicos da língua-alvo inseriram mais a vogal de apoio do que os aprendizes sem instrução, conforme mostra o Gráfico 1.

Gráfico 1: Porcentagem de inserção vocálica no GC e GE

\section{Inserção vocálica}

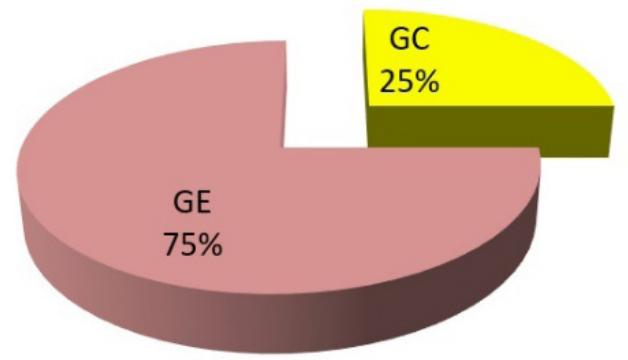

Fonte: As autoras.

No entanto, ao verificar outros aspectos acústicos envolvidos na produção dos dois grupos, percebemos que eles se distinguem quanto a aspectos duracionais dos segmentos oclusivos, o que nos leva a refletir se essa diferença tem relação com o nível de conhecimento que os aprendizes demonstram acerca da fonologia da língua-alvo. 
Em relação ao GE, pudemos observar que a duração da consoante oclusiva em coda é maior quando o aprendiz não insere a paragoge (vogal de apoio). Vejamos como isso se materializa nas Figuras 5 e 6.

Figura 5: Palavra second - GE - sem paragoge - medida em milissegundos da oclusiva

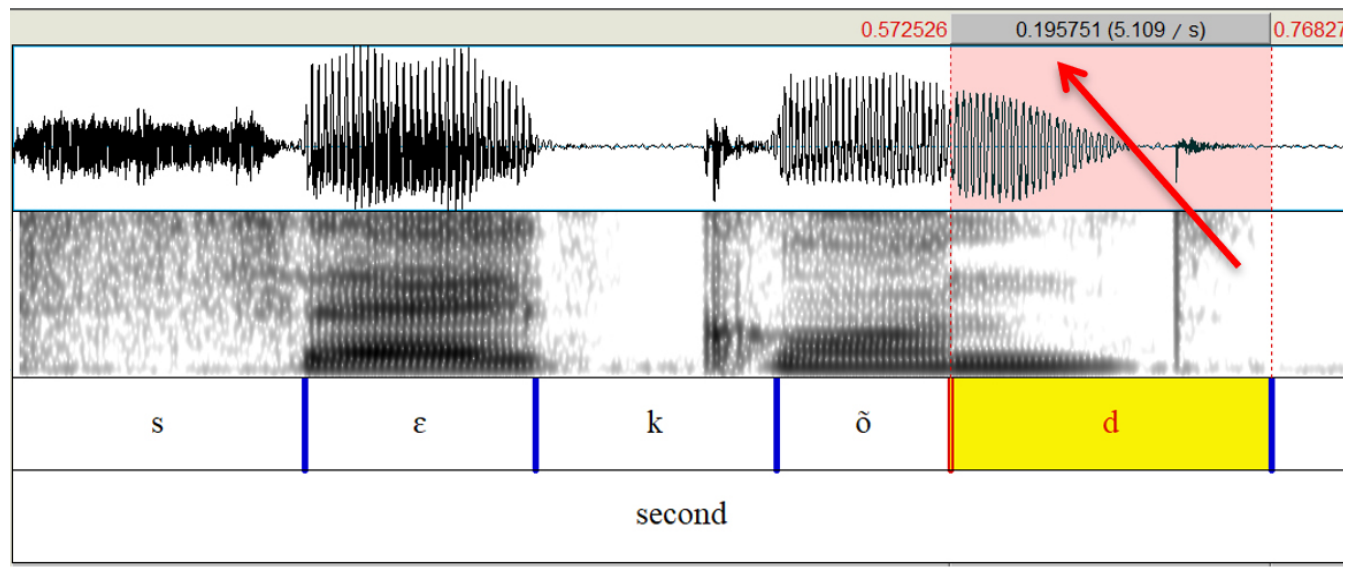

Fonte: As autoras.

Figura 6: Palavra second - GE - com paragoge - medida em milissegundos da oclusiva

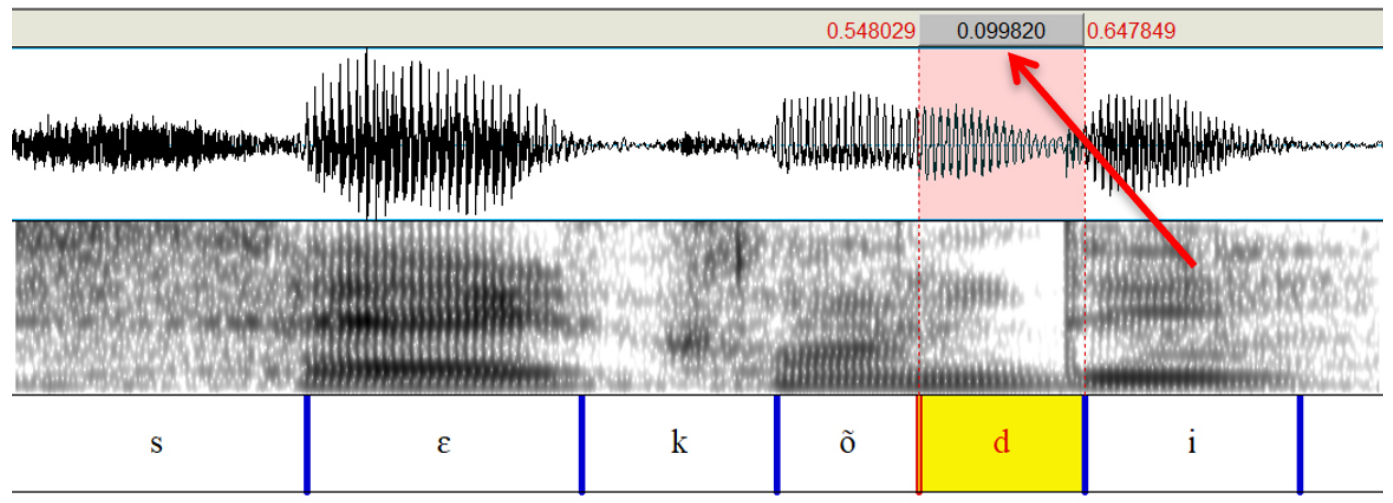

second

Fonte: As autoras.

Conforme mostram as Figuras 5 e 6, os valores duracionais em milissegundos (ms) da oclusiva no GE são bastante diferentes a depender da estratégia utilizada pelo aprendiz. Na Figura 5, em que não houve a inserção vocálica, ou seja, o aprendiz parece produzir a estrutura silábica da língua-alvo (CVC), obtemos uma duração de 195 ms para a oclusiva alveolar vozeada em coda [d]; em contrapartida, quando há a reestruturação ao molde CV do PB, com a inserção da vogal, mostrada na Figura 6, a duração do mesmo segmento mostra-se bastante inferior (099ms). Os valores duracionais da palavra na produção dos dois grupos são muito próximos, 
766ms no GE e 776ms no GC, o que demonstra que a diferença na duração da oclusiva não foi influenciada pela velocidade de fala, conforme nos mostram as Figuras 7 e 8.

Figura 7: Palavra second - GE - duração total da palavra

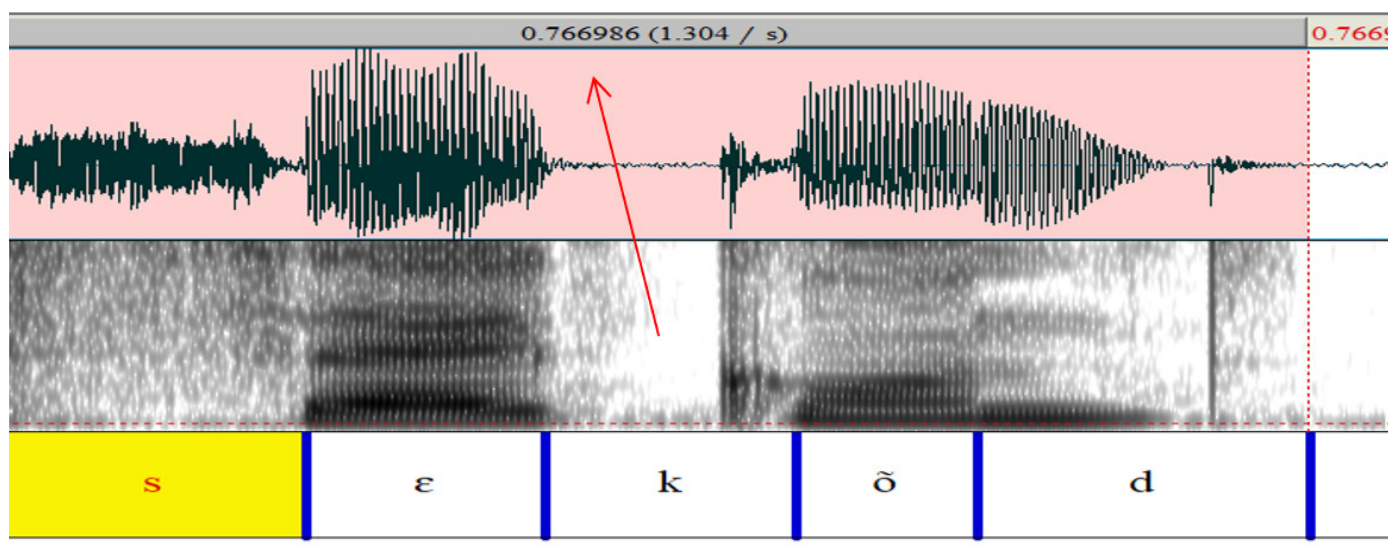

second

Fonte: As autoras.

Figura 8: Palavra second - GE - duração total da palavra

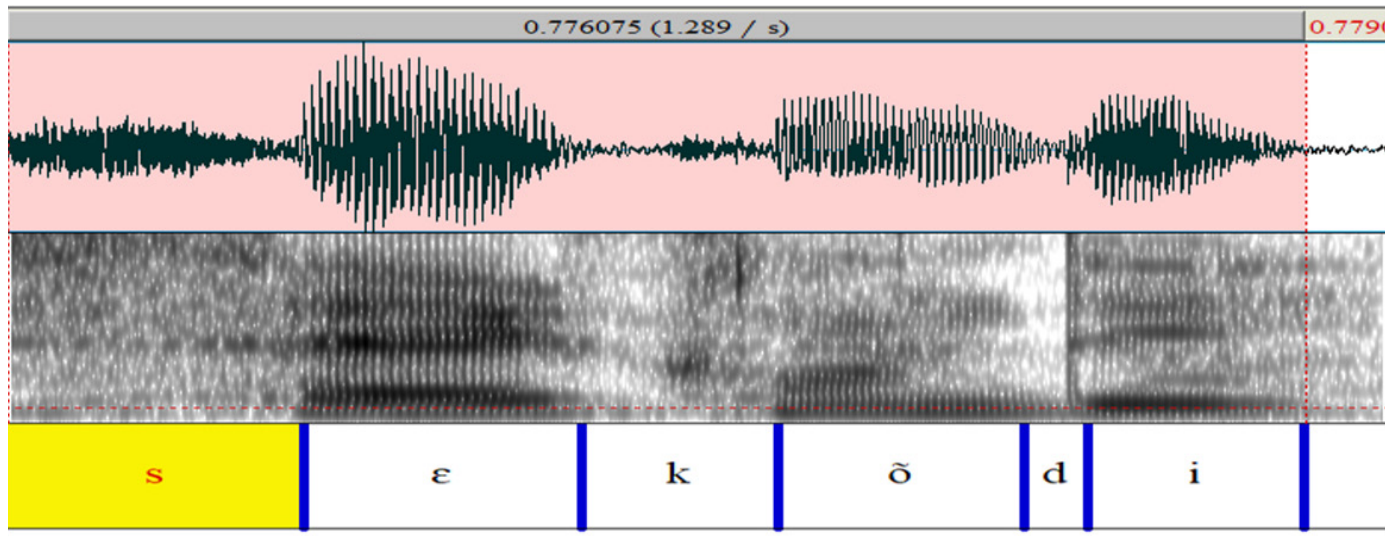

second

Fonte: As autoras.

Tais valores nos levam a questionar se o falante da Figura 5 obteve uma produção semelhante ao padrão nativo, visto que parece compensar a ausência vocálica no segmento em coda.

Em relação ao GC, a estratégia mais comum foi o apagamento da oclusiva em coda. Observemos a Figura 9, antes de mais comentários. 
Figura 9: Apagamento da oclusiva em coda na palavra second - GC

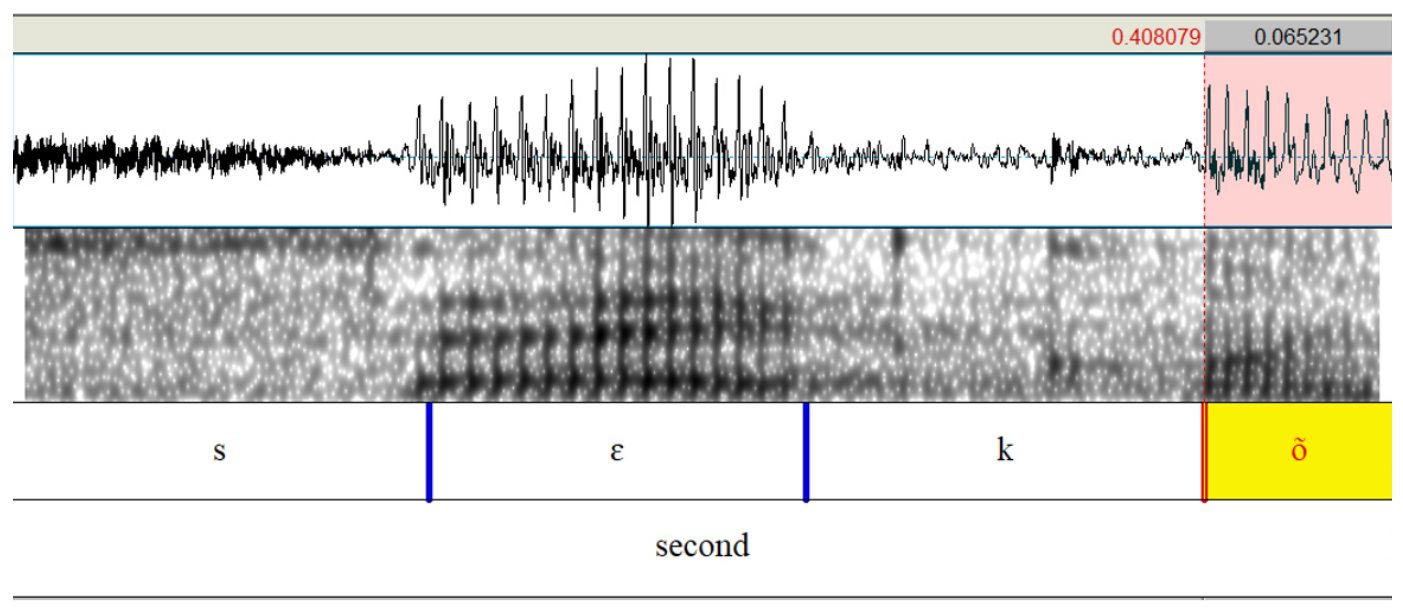

Fonte: As autoras.

Conforme constatamos na Figura 9, os falantes do GC, sem instrução explícita acerca dos aspectos fonético-fonológicos da língua inglesa, apagaram o segmento oclusivo em coda, o que favorece a uma produção comum ao padrão silábico do sistema linguístico do PB: o padrão $\mathrm{CV}$. Os resultados permitem interpretar que os aprendizes do GE, apesar de realizarem a reestruturação silábica por meio da inserção da vogal, lançam mão de estratégias compensatórias, que aproximam sua produção ao padrão fonológico da língua-alvo, algo que não ocorre com o GC, devido a esse grupo apresentar o apagamento do elemento da coda silábica, distanciando sua produção do molde silábico CVC da língua inglesa.

Os resultados obtidos pelos dados coletados com os dois grupos sugerem que a busca pelo desenvolvimento da CF, por meio de instrução explícita, favorece melhores resultados quanto ao nível silábico da L2. Mesmo diante da inserção vocálica após a oclusiva, no GE, há uma melhor preservação do molde silábico CVC da língua-alvo do que no GC, ao apagar a consoante oclusiva em coda, o que pode ocasionar, ainda, prejuízos comunicativos maiores do que as estratégias utilizadas pelo GE.

\section{CONSIDERAÇÕES FINAIS}

Este trabalho buscou, como objetivo geral, verificar como os falantes brasileiros aprendizes da língua inglesa como L2 produziam o molde silábico CVC da língua-alvo, em que a coda é uma consoante oclusiva. Para termos um parâmetro de comparação, tais falantes foram divididos em dois grupos distintos: um grupo com instrução explícita (GE) e um grupo sem instrução explícita (GC) acerca dos padrões fonológicos da língua inglesa.

Os resultados, à primeira vista, demonstraram um aspecto bastante curioso: o GC obteve uma produção de vogal de apoio bastante inferior, em comparação ao GE. No entanto, um olhar mais profundo para os aspectos acústicos encontrados nos dados dos aprendizes demonstrou que as estratégias do GE foram muito distintas do GC. No que diz respeito ao GE, podemos observar 
que a ausência da vogal de apoio provoca uma mudança duracional na consoante oclusiva em coda, como se o falante estivesse compensando a ausência vocálica, nos levando a refletir que há processos variáveis interessantes ocorrendo na produção da estrutura silábica CVC da língua inglesa pelos aprendizes brasileiros que receberam instrução explícita. O apagamento da oclusiva em coda pelos aprendizes do GC, além de não demonstrar desenvolvimento da CF na L2, pode comprometer o processo comunicativo, visto que traz prejuízos ao reconhecimento lexical.

A pesquisa leva-nos a refletir acerca da importância da CF quanto aos aspectos base dos sistemas linguísticos, os aspectos fonético-fonológicos, em que esta, ao ocorrer em um continuum, proporciona maiores processos variáveis, o que demonstra que a língua está em desenvolvimento. Estudos futuros devem elencar uma quantidade maior de dados, bem como investigar que outros processos variáveis ocorrem ao estimular o desenvolvimento da CF, a fim de fornecer resultados de estratégias utilizadas pelos aprendizes quando estes tentam aproximar sua fala ao sistema-alvo.

\section{REFERÊNCIAS}

ALVES, A. C. Análise variacionista da produção da fricativa interdental surda do inglês /ө/ por aprendizes brasileiros. 2018. Dissertação (Mestrado em Linguística) - Universidade Federal da Paraíba, João Pessoa, 2018.

ALVES, U. K. Consciência dos aspectos fonético-fonológicos da L2. In: LAMPRECHT, R. R.; BLANCO-DUTRA, A. P. et al. (org.). Consciência dos sons da língua: subsídios teóricos e práticos para alfabetizadores, fonoaudiólogos e professores da língua inglesa. 2. ed. Porto Alegre: EDIPUCRS, 2012. p. 169-190.

BARBOSA, P. A; MADUREIRA, S. Manual de fonética acústica experimental - Dados aplicados ao português brasileiro. São Paulo: Cortez Editora, 2015.

BOERSMA, P.; WEENINK, D. Praat: doing phonetics by computer. Version 6.0.21, 2017. Disponível em: www.praat.org. Acesso em: 10 jul. 2020.

CHARD, D.; DICKSON, S. Phonological awareness: instructional and assessment guidelines. Intervention in School and clinic, [s. l.], v. 34, n. 5, p. 261-70, 1999.

COLLISCHONN, G. A sílaba em português. In: BISOL, L. (org.). Introdução a estudos de fonologia do português brasileiro. Porto Alegre: EDIPUCRS, 2014. p. 115.

PEDROSA, J. L. R. Sílaba. In: HORA, D. da; PEDROSA, J. L. R. (org.). Introdução à fonologia do português brasileiro. João Pessoa: Editora da UFPB, 2012. p. 74.

SELKIRK, E. The syllable. In: HULST, H.; SMITH N. (org.). The structure of phonological representations. Foris: Dordrecht, 1982. p. 344.

Recebido em: jun. 2020.

Aceito em: ago. 2020. 